\title{
A randomized controlled trial testing the efficacy of a brief cannabis universal prevention program among adolescents in primary care
}

\author{
Maureen A. Walton', Stella Resko², Kristen L. Barry',3, Stephen T. Chermack ${ }^{1,3}$, \\ Robert A. Zucker', Marc A. Zimmerman', Brenda M. Booth ${ }^{5,6}$ \& Frederic C. Blow ${ }^{1,3}$ \\ Department of Psychiatry, University of Michigan, Ann Arbor, MI, USA,' Wayne State University School of Social Work and Merrill Palmer Skillman Institute, Detroit, \\ MI, USA, ${ }^{2}$ Department of Veterans Affairs, Center for Clinical Management Research, Health Services Research and Development, Ann Arbor, MI, USA, ${ }^{3}$ University \\ of Michigan, School of Public Health, Ann Arbor, MI, USA, ${ }^{4}$ Department of Psychiatry, University of Arkansas for Medical Sciences, Little Rock, AR, USA ${ }^{5}$ and Central \\ Arkansas Veterans Healthcare System, Little Rock, AR, USA
}

\begin{abstract}
Aims To examine the efficacy of a brief intervention delivered by a therapist (TBI) or a computer (CBI) in preventing cannabis use among adolescents in urban primary care clinics. Design A randomized controlled trial comparing: CBI and TBI versus control. Setting Urban primary care clinics in the United States. Participants Research staff recruited 714 adolescents (aged 12-18 years) who reported no life-time cannabis use on a screening survey for this study, which included a baseline survey, randomization (stratified by gender and grade) to conditions (control; CBI; TBI) and 3-, 6- and 12-month assessments. Measurements Using an intent-to-treat approach, primary outcomes were cannabis use (any, frequency); secondary outcomes included frequency of other drug use, severity of alcohol use and frequency of delinquency (among 85\% completing follow-ups). Findings Compared with controls, CBI participants had significantly lower rates of any cannabis use over 12 months $(24.16 \%, 16.82 \%$, respectively, $P<0.05)$, frequency of cannabis use at 3 and 6 months $(P<0.05)$ and other drug use at 3 months $(P<0.01)$. Compared with controls, TBI participants did not differ in cannabis use or frequency, but had significantly less other drug use at 3 months $(P<0.05)$, alcohol use at 6 months $(P<0.01)$ and delinquency at 3 months $(P<0.01)$. Conclusions Among adolescents in urban primary care in the United States, a computer brief intervention appeared to prevent and reduce cannabis use. Both computer and therapist delivered brief interventions appeared to have small effects in reducing other risk behaviors, but these dissipated over time.
\end{abstract}

Key words Adolescent, alcohol, brief intervention, cannabis, computerized, delinquency, drug, prevention, primary care, urban.

Correspondence to: Maureen A. Walton, University of Michigan, Department of Psychiatry, 2800 Plymouth Road, Building 16, Ann Arbor, MI 48109, USA. E-mail: waltonma@umich.edu

Submitted 11 April 2013; initial review completed 19 June 2013; final version accepted 12 December 2013

\section{INTRODUCTION}

Although, in the United States, alcohol is the most prevalent substance used by adolescents, cannabis is the most prevalent illicit drug, with rates increasing with age [1]. Non-medical use of prescription drugs is the next most commonly reported substance [1]. Earlier age of cannabis use increases the risk for other drug use, psychosocial problems (e.g. delinquency) and the development of substance use disorders [2-4].

Traditionally, multi-session substance use prevention programs have been delivered in schools, with evidencedbased programs for alcohol, cannabis and illicit drug use
[5-13]. Findings from a meta-analysis suggest that universal programs were more effective for low base rates of use (e.g. tobacco, marijuana) and selective or indicated programs were more effective for high base rates of use (e.g. alcohol) [13]. School-based prevention programs have limited ability to reach youth who have dropped out of school or attend sporadically.

A visit to a primary care clinic increases the reach of prevention programs and may provide a 'teachable moment' for brief interventions (BIs), increasing adolescents' receptivity to interventions [14]. In order to reduce health disparities in access to primary care services among socio-economically disadvantaged populations, 
the US government has established federally qualified health clinics (FQHCs). BIs encompass principles of harm reduction and motivational interviewing, which may be particularly well suited for adolescents [14,15].

The application of BIs focused on universal prevention among non-using youth is generally lacking. Prior BI research has taken a selective or indicated approach, with meta-analyses demonstrating efficacy [16]. For example, among adolescent drinkers in primary care, therapist BIs decrease alcohol misuse [17-21]. Among drug users, there are a few promising pilot studies of therapist BIs [18,22-24] and an effective trial in the Czech Republic [21]. A prior paper from the study described in this paper showed that among youth using cannabis, a therapist BI reduced driving under the influence of cannabis, but did not affect use [25]. A recent study found a universal prevention-focused therapist BI for adolescent substance use was not efficacious, despite the fact that content was adapted from a previously demonstrated efficacious selective prevention-focused therapist BI [26-28].

Using computers for the assessment and delivery of universal prevention-focused BIs could have considerable public health impact. Although such studies are lacking among adolescents in primary care, among adolescents in the emergency department (ED) [29] and college students [30,31], universal prevention-focused, computerdelivered alcohol BIs are effective in the short term and/or with at-risk subgroups of participants. A prior manuscript from the study described in this paper examining cannabis users showed that a selective computer BI decreased other drug use and cannabis-related consequences but not cannabis use [25].

This paper presents data from a randomized controlled trial (RCT) examining the efficacy of universal prevention-focused BIs (therapist- or computer-delivered) in comparison to a control condition among adolescents (aged 12-18 years) who had not initiated cannabis use presenting to urban FQHCs. Preliminary outcome variables measured at post-test included perceived risk, selfefficacy and intention to use. The primary outcome measure was initiation and frequency of cannabis use; the secondary outcome measures were frequency of other drug use, severity of alcohol use and frequency of delinquency. Hypotheses were that participants in the BIs would report less cannabis, alcohol, other drug use (illicit and non-medical prescription) and delinquency than controls at 3-, 6- and 12-month follow-ups.

\section{METHOD}

\section{Design}

Project Chill was conducted at seven urban FQHCs in the Midwest (April 2007-December 2009). Adolescents (aged 12-18 years) self-administered a computerized screening survey (with audio). Participants who had not initiated cannabis use were enrolled in the RCT, consisting of a baseline assessment, randomization to one of three conditions (computer BI, therapist BI or control) and follow-up assessments at 3, 6 and 12 months. Participants reporting past-year cannabis use were enrolled into a parallel trial reported on elsewhere [25]. The study was approved by the University of Michigan's Institutional Review Board (IRB) for Human Subjects and we obtained a Certificate of Confidentiality.

\section{Procedures}

On days containing a greater concentration of adolescent appointments, research staff recruited patients in treatment or waiting rooms. A two-phase written assent (youth aged 12-17 years) and/or consent (youth aged 18, parents of youth aged 12-17) procedure was used for the screening and RCT. Participants self-administered the 10-minute computer screening survey and received a token \$1.00 gift. Initially (April 2007-July 2008), participants who reported no life-time cannabis use were eligible for the RCT. In order to increase the proportion of males in the RCT and slow participant accrual, halfway through the study (July 2008-December 2009) 50\% of the males and $10 \%$ of the females with no prior cannabis use were selected randomly for the RCT, after which time enrollment ended as planned based on funding. Then, youth completed a 25-minute baseline computer survey (\$20 remuneration) and provided a urine sample for drug testing (\$5). Participants were assigned randomly to conditions by research staff using a computerized algorithm, which was monitored by the project coordinator and data manager to ensure that staff could not manipulate assignment. Randomization was stratified by gender (in blocks of 21 ; seven per group) and grade (6-8th; 9 th and up including dropouts). The computerized post-test was administered following the BIs. Research staff contacted youth (e.g. telephone call, text, e-mail or private messaging via social networking sites) to schedule follow-ups, which occurred at primary care offices $(85 \%)$, homes $(7 \%)$, other community locations $(6 \%)$ or by telephone $(2 \%)$. Youth received remuneration of $\$ 25, \$ 30$ and $\$ 35$ at each assessment, respectively (and $\$ 5$ for a urine sample at each follow-up). Follow-up staff were blinded to condition assignment.

\section{Measures}

In addition to demographic items [i.e. age, gender, race, ethnicity, grade level (6-8th; 9th and up including dropouts), grades in school (mostly As, As and Bs, mostly Bs, Bs and Cs, mostly Cs, Cs and Ds, mostly Ds, Ds and Fs, mostly Fs)] [32,33], validated measures are described below. 


\section{Post-test preliminary outcomes}

Perceived risk. Two items [34] were summed to indicate perceived risk of occasional and regular cannabis use $(r=0.54)$. Response choices included: no (0), slight (1), moderate (2) and great (3).

Self-efficacy. Confidence in refusing cannabis use in three situations (i.e. party, home alone and feeling sad or bored, hanging out at a friend's house) [35] was assessed by summing responses to a five-point Likert scale [ranging from 'not at all sure I could say no' (1) to 'completely sure I could say no' (5) $(\alpha=0.86)]$.

Intention to use. A single item assessed intention to use cannabis in the next 3 months, with responses ranging from 'strongly disagree' (1) to 'strongly agree' (4) [35].

\section{Primary outcomes}

Cannabis. Cannabis (e.g. marijuana, weed, pot) use frequency (past 3 months) was measured using a question from the Add Health study [32,33]. Response choices were: never, 1-2 days, once a month or less, 2-3 days per month, 1-2 days per week, 3-5 days per week and every day or almost every day. Variables included any cannabis use and frequency of use (range 0-6).

\section{Secondary outcomes}

Alcohol. The Alcohol Use Disorders Identification Testconsumption (AUDIT-C) [36] was used to assess frequency, quantity and heavy drinking (five or more) [37] in the past 3 months. During piloting, youth indicated that question 1 response options [never (0), monthly or less (1), two to four times a month (2), two to three times a week (3), four or more times a week (4)] were confusing; thus, we substituted the response options for question 3 [never (0), less than monthly (1), monthly (2), weekly (3), daily or almost daily (4)]. For quantity, the responses were: (0) none, (1) one to two, (2) three to four, (3) five to six, (4) seven to nine (5) and 10 or more. Items were summed to create an alcohol use severity scale (range 0-13).

Other drugs. Illicit and non-medical prescription drug use (on your own without a doctor telling you to take them) in the past 3 months was measured using questions from the Add Health study [32,33]. Illicit drugs included: inhalants, cocaine, heroin and other hallucinogens (e.g. ecstasy). Non-medical prescription drugs included: painkillers/opiates (e.g. codeine); stimulants (e.g. Ritalin); and sedatives (e.g. Xanax). Response options ranged from 0-6: never, 1-2 days, once a month or less, 2-3 days per month, 1-2 days per week, 3-5 days per week, every day or almost every day. Items were summed to create a frequency of other drug use variable (range 0-42).

Delinquency. Ten items assessing frequency of violent and non-violent delinquency in the past 3 months [38] (e.g. physical fighting, stealing, selling drugs) were summed, with responses ranging from 0 to 10 or more times $(\alpha=0.85$; range $0-100)$.

\section{Project Chill BIs}

BIs were conducted in a private room and could be paused to allow for medical care. The BIs integrated motivational interviewing (MI) spirit and techniques [14,15,39], emphasizing personal responsibility, supporting selfefficacy, eliciting commitment talk for avoiding cannabis use and change talk for reducing alcohol, other drugs and delinquency (see Table 1). The BIs also included normative resetting and role-play scenarios. Cultural relevance to address the study population ( $50 \%$ African American) was incorporated into the content based on feedback from focus testing, including providing diversity in language (key messages, scripts for $\mathrm{CBI}$ ), item-listed checkboxes (e.g. goals, reasons to avoid using) and scenario topics.

TBI. Therapists were trained in MI [14,15], including the use of rulers to increase self-efficacy and commitment talk for abstinence/reduction of other risk behaviors (average length $=38$ minutes, standard deviation $=14$ ). A computer displayed tailored feedback and prompt content. Fidelity was monitored by audio-taping and providing feedback via regular individual and group supervision. A random sample of tapes was coded $(25.8 \%$, $n=61$ ) for therapist competence [global rating of MI therapist (GROMIT); 18 items, $\alpha=0.94$ ] [40] and content adherence ( 15 items, $\alpha=0.80$; developed for this study) using a seven-point Likert scale (ranging from 1 , 'very poor' to 7, 'expert mastery'). Mean scores were generally acceptable for the GROMIT, indicating MI spirit and skill [4.95; standard deviation $(\mathrm{SD})=0.58$; range 4-6] and content adherence (3.85; SD $=0.40$; range 3-6), indicating delivery of sections.

CBI. Using touch-screens and headphones for audio, the CBI was an animated, interactive program (average length $=33$ minutes, standard deviation $=13$ ) delivered by a virtual therapist, who provided affirmations and summaries. Guided by a buddy chosen by participants, the role-play scenarios showed characters in risky situations, with progression over time in various consequences, eliciting participant interaction and rolemodeling positive choices. 
Table 1 Key elements of project CHILL prevention interventions.

\begin{tabular}{|c|c|c|}
\hline Key elements & Goal of element & $\begin{array}{l}\text { Computer }(C) \text { - and therapist (T)-specific content or } \\
\text { both }(B)\end{array}$ \\
\hline What are we going to do & $\begin{array}{l}\text { - Establish rapport } \\
\text { - Explain purpose to talk about cannabis use }\end{array}$ & $\begin{array}{l}\text { C: Virtual therapist; participant selects buddy } \\
\text { T: Therapist introduction }\end{array}$ \\
\hline $\begin{array}{l}\text { What's important to you: } \\
\text { goals and values }\end{array}$ & $\begin{array}{l}\text { - Review and elaborate on goals and values } \\
\text { - Begin to develop discrepancy between } \\
\text { goals/values and current behavior by } \\
\text { exploring how cannabis use fits in with } \\
\text { goals/values }\end{array}$ & $\begin{array}{l}\text { B: } 3 \text { goals listed } \\
\text { C: Summary of goals } \\
\text { T: Brief discussion of goals }\end{array}$ \\
\hline $\begin{array}{l}\text { Where do I fit in: normative } \\
\text { feedback }\end{array}$ & $\begin{array}{l}\text { - Compare survey responses for use of } \\
\text { cannabis and alcohol to norms for age and } \\
\text { gender } \\
\text { - Raise concern by providing feedback about } \\
\text { the association between cannabis and other } \\
\text { risk behaviors (e.g. alcohol, other drugs) and } \\
\text { consequences (e.g. violence, injury, } \\
\text { delinquency, arrests) } \\
\text { - Explore potential impact of use on } \\
\text { goals/values, strengthening commitment talk } \\
\text { for avoiding/reducing use }\end{array}$ & $\begin{array}{l}\text { B: Gender/age appropriate graphs shown on } \\
\text { screen } \\
\text { B: Reviewed in a matter-of-fact, } \\
\text { non-judgmental manner } \\
\text { T: Discuss how currently or in the future could } \\
\text { impact goals } \\
\text { C: Ask if think affects goals, check response on } \\
\text { screen; reflective summary statements } \\
\text { provided } \\
\text { C: Pictorial illustrations fading in and out to } \\
\text { increase salience during messages }\end{array}$ \\
\hline $\begin{array}{l}\text { You decide: reasons for } \\
\text { avoiding using/reasons } \\
\text { for using }\end{array}$ & $\begin{array}{l}\text { - Elicit reasons to avoid using cannabis } \\
\text { - Explore reasons why other kids use cannabis } \\
\text { - Elicit and affirm commitment talk } \\
\text { - Support self-efficacy for avoiding use } \\
\text { - Support avoiding use by exploring potential } \\
\text { impact of use on future goals/values } \\
\text { - Roll with resistance } \\
\text { - Emphasize participant responsibility for } \\
\text { making choices }\end{array}$ & $\begin{array}{l}\text { B: Reasons for avoiding cannabis use (long list) } \\
\text { and reasons for using (short list) presented } \\
\text { on screen for participant to check } \\
\text { T: Use motivational interviewing (MI) strategies } \\
\text { to make a connection between reasons to } \\
\text { avoid these behaviors and goals } \\
\text { C: Summaries of the reasons checked on the } \\
\text { screen. Participant checks which of goals } \\
\text { could be affected by use, which is } \\
\text { summarized }\end{array}$ \\
\hline $\begin{array}{l}\text { What's next: } \\
6 \text { role plays }\end{array}$ & $\begin{array}{l}\text { - Practice } 6 \text { scenarios which were selected by } \\
\text { the computer based on gender and risk profile } \\
\text { obtained from assessment } \\
\text { - Role-plays focus on: refusal skills with low } \\
\text { peer pressure, refusal skills with high peer } \\
\text { pressure, driving high/drunk or riding with } \\
\text { someone high/drunk, delinquency, coping } \\
\text { with boredom, refusal skills focusing on } \\
\text { consequences of use }\end{array}$ & $\begin{array}{l}\text { B: Parallel role-play scenarios } \\
\text { T: Options are discussed to provide tools for } \\
\text { risky scenarios } \\
\text { C: Animated video situations viewed with } \\
\text { buddy. Decision points where participant } \\
\text { chooses the next action. If participants } \\
\text { 'choose' a negative choice (use), the buddy } \\
\text { gives feedback on consequences in relation to } \\
\text { goals. Participant chooses a better option, } \\
\text { which is then animated } \\
\text { Scenarios show progression in consequences } \\
\text { for characters who use and don't use }\end{array}$ \\
\hline $\begin{array}{l}\text { What we covered: summary } \\
\text { of session }\end{array}$ & $\begin{array}{l}\text { - Provide participant with summary of goals, } \\
\text { behaviors, reasons to stay away from } \\
\text { cannabis } \\
\text { - Strengthen commitment to avoid using } \\
\text { - Support self-efficacy } \\
\text { - Review key messages and community } \\
\text { resources handout (e.g. mentor, psychological } \\
\text { services, leisure activities) } \\
\text { - Identify one next step in avoiding cannabis }\end{array}$ & $\begin{array}{l}\text { T: Summary to reinforce commitment talk; } \\
\text { support/ advice for their 'plan'. Review } \\
\text { community resources with an emphasis on } \\
\text { risk profile } \\
\text { C: Summaries of goals and reasons checked to } \\
\text { stay away from cannabis. Review of key } \\
\text { prevention messages; encourages review of } \\
\text { the community resources handout }\end{array}$ \\
\hline
\end{tabular}

Control. Participants in the control (and the BIs) were given a brochure containing warning signs of problems with cannabis and community resources (e.g. substance use, mental health and leisure activities).

\section{Data analysis}

SAS version 9.2 was used for analyses. Descriptive data are presented regarding enrollment and baseline 
characteristics by condition assignment; bivariate analyses were conducted to examine equivalence of groups at baseline $\left(\chi^{2} ; t\right.$-tests $)$. Preliminary outcome analyses examined within condition (TBI, CBI) changes from baseline to post-test on perceived risk, self-efficacy and intentions (using the paired Wilcoxon's signed-rank test due to skewed variable distributions).

Study aims were to prevent or delay initiation of cannabis use and reduce the extent of involvement with cannabis use, alcohol use, other drug use and delinquency. Although 97\% received their assigned condition, an intent-to-treat approach was used (e.g. all randomized participants included regardless of whether condition was received). Participants missing at follow-up are not included in the analyses; however, follow-up rates exceeded $85 \%$ for all conditions over time and attrition analyses showed that baseline variables were not significantly related to follow-up completion, suggesting that the data were missing at random. First, the percentage point difference for any cannabis use was compared by conditions (TBI, CBI) versus control at each time-point (3, 6 and 12 months), as well as cumulatively over 12 months, using Fisher's exact test (with 95\% confidence intervals). Secondly, regression analyses (i.e. negative binominal or Poisson models based on distribution) were conducted to predict continuous primary (cannabis use frequency) and secondary (i.e. other drug use frequency, alcohol use severity and delinquency frequency) outcomes at 3, 6 and 12 months. Independent variables included baseline levels of the variable examined and condition (TBI versus control, CBI versus control). The study was not powered to detect differences between BIs. Thirdly, for conservative purposes, we repeated the regression analyses described above, controlling for baseline variables: gender, grade level (6-8th; 9th and up including dropouts), Hispanic ethnicity, race (African American versus other) and failing grades (D and below or dropped out). Age was not included, as it was correlated 0.91 with grade level.

To achieve $80 \%$ power, $n=199$ per group were needed to detect a $10 \%$ difference in outcomes. Cohen's effect sizes [38] were calculated for significant effects. Effect sizes of $d=0.10$ are considered clinically meaningful in the prevention literature [41].

\section{RESULTS}

\section{Participants}

Overall, 1416 youth were screened (Fig. 1). Males were more likely to refuse participation in the screening than females (18.0 and $12.9 \%$, respectively; $\chi_{(1)}^{2}=8.18$, $P<0.05)$. Also, Caucasians were more likely to refuse than African Americans and other races (21.9, 12.8 and $15.6 \%$, respectively; $\left.\chi^{2}(2)=14.72, P<0.001\right)$.

Among those screened, 714 reported no prior cannabis use, completed the baseline and were enrolled into the RCT. Although no gender differences were observed for participation in the baseline $(3.6 \%$ male, $3.7 \%$ female; $\left.\chi^{2}{ }^{2}(1)=0.0157, P>0.05\right)$, Caucasians were more likely to refuse than were African Americans and other races (6.0, 3.9 and $1.3 \%$, respectively; $\chi^{2}{ }_{(2)}=6.86$ and $\left.P<0.05\right)$. No other information could be gathered on those who refused without written informed consent. Baseline characteristics were examined for equivalence by condition; age and grade level were significantly different by condition assignment (Table 2). Note that participants reporting past-year cannabis use $(n=366$; see [25]) or cannabis use that occurred greater than 1 year ago $(n=31)$ were excluded from the prevention study.

Most youth (93.4\%; 667 of 714) completed their condition immediately or within 2 weeks $(n=24)$; youth who did not receive their BI $(n=23)$ were included in followups. Follow-up rates exceeded $85 \%$ at 3, 6 and 12 months. $\chi^{2}$ analyses comparing attrition rates by group showed no evidence of differential drop-out by condition at 6 or 12 months ( $P$ values $>0.05$ ). At 3 months, the TBI group had significantly lower follow-up rates than the control (85.4 versus 92.3\%; $\left.\chi^{2}{ }_{(1)}=5.61, P<0.05\right)$; attrition did not differ at 3 months for the CBI versus control. Comparisons of those completing follow-ups at 3, 6 and 12 months with those who did not complete follow-ups were not significant for variables shown in Table 2 .

Concordance between past 3-month self-report and urine drug screen for cannabis was excellent at baseline (99.4\%). At 3, 6 and 12 months, agreement remained high (99.0\%); thus, self-report was used for analyses.

\section{Preliminary outcomes}

At post-test (Table 3), significant increases were noted in perceived risk (for the CBI but not TBI) and in self-efficacy (for the CBI and TBI). No significant changes were found for behavioral intentions, probably because at baseline most adolescents reported 'strongly disagree' for intention to use.

\section{Primary and secondary outcomes}

Cannabis use

Table 4 shows the point prevalence of any cannabis use by condition over time. For the CBI, although the point prevalence did not differ at each time-point, the cumulative prevalence over 12 months was significantly lower in the CBI compared to the control. The point prevalence of cannabis use did not differ for the TBI versus the control. 
Frequency outcomes: cannabis, other drugs, alcohol, delinquency

Models are presented that do not control for demographics (Table 5). Compared to controls, participants in the CBI showed significantly less cannabis use at 3 and 6 months ( $d=0.12$ and 0.14 , respectively) and other drug use at 3 months $(d=0.09)$; the CBI did not affect alcohol use or delinquency (Table 5). Although participants in the TBI did not differ significantly from controls in can- nabis use, participants in the TBI showed significantly less other drug use at 3 months $(d=0.03)$, delinquency at 3 months $(d=0.36)$ and alcohol use at 6 months $(d=0.14)$ compared to controls. No significant effects were observed at 12 months.

Additional models controlled for demographics (i.e. gender, grade level, race, failing grades, ethnicity; Table 6). Findings for the CBI were identical, as reported above. Findings for the TBI were similar, with the exception that the efficacy of the TBI on other drug use was not

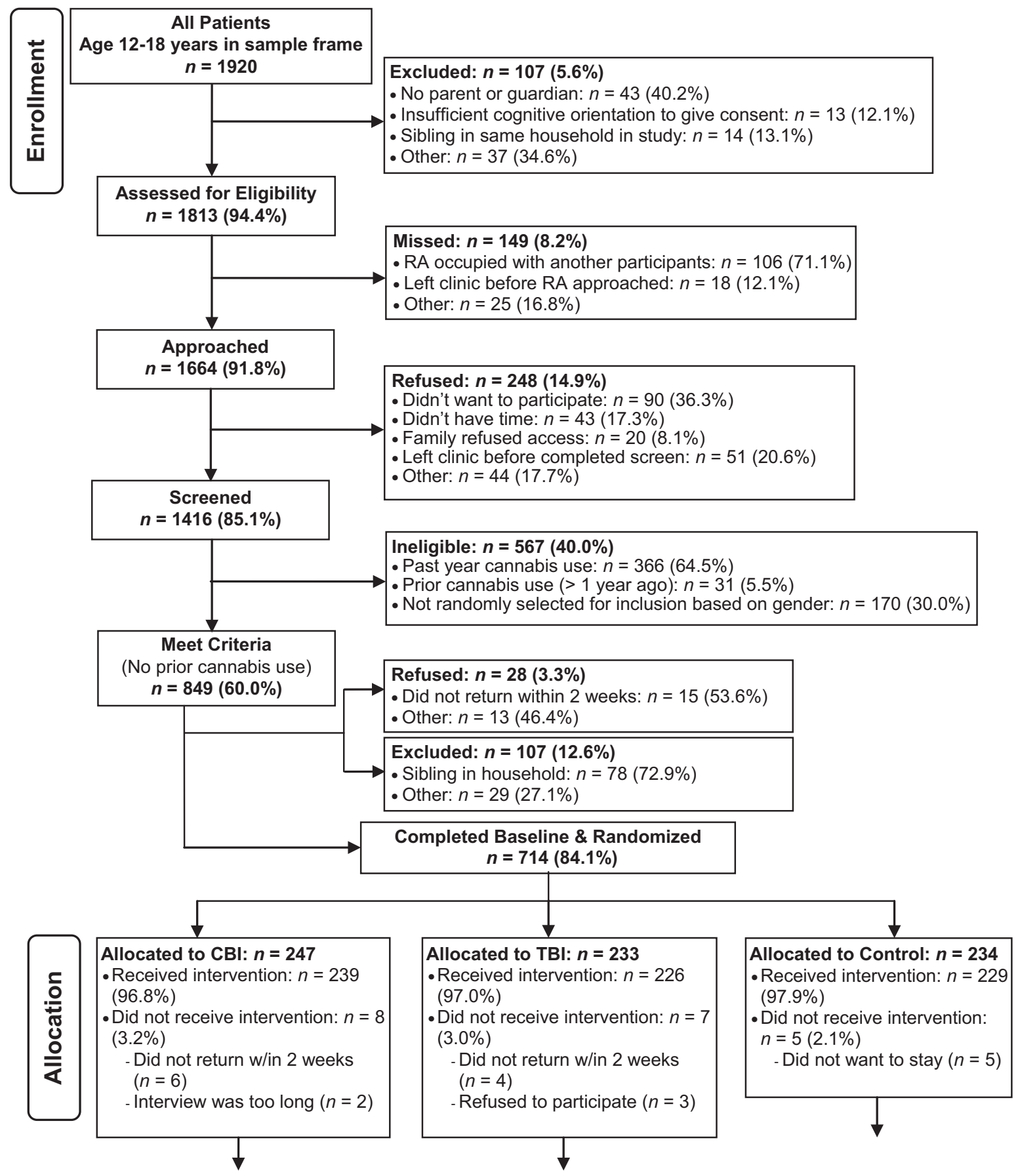

Figure I Study enrollment 

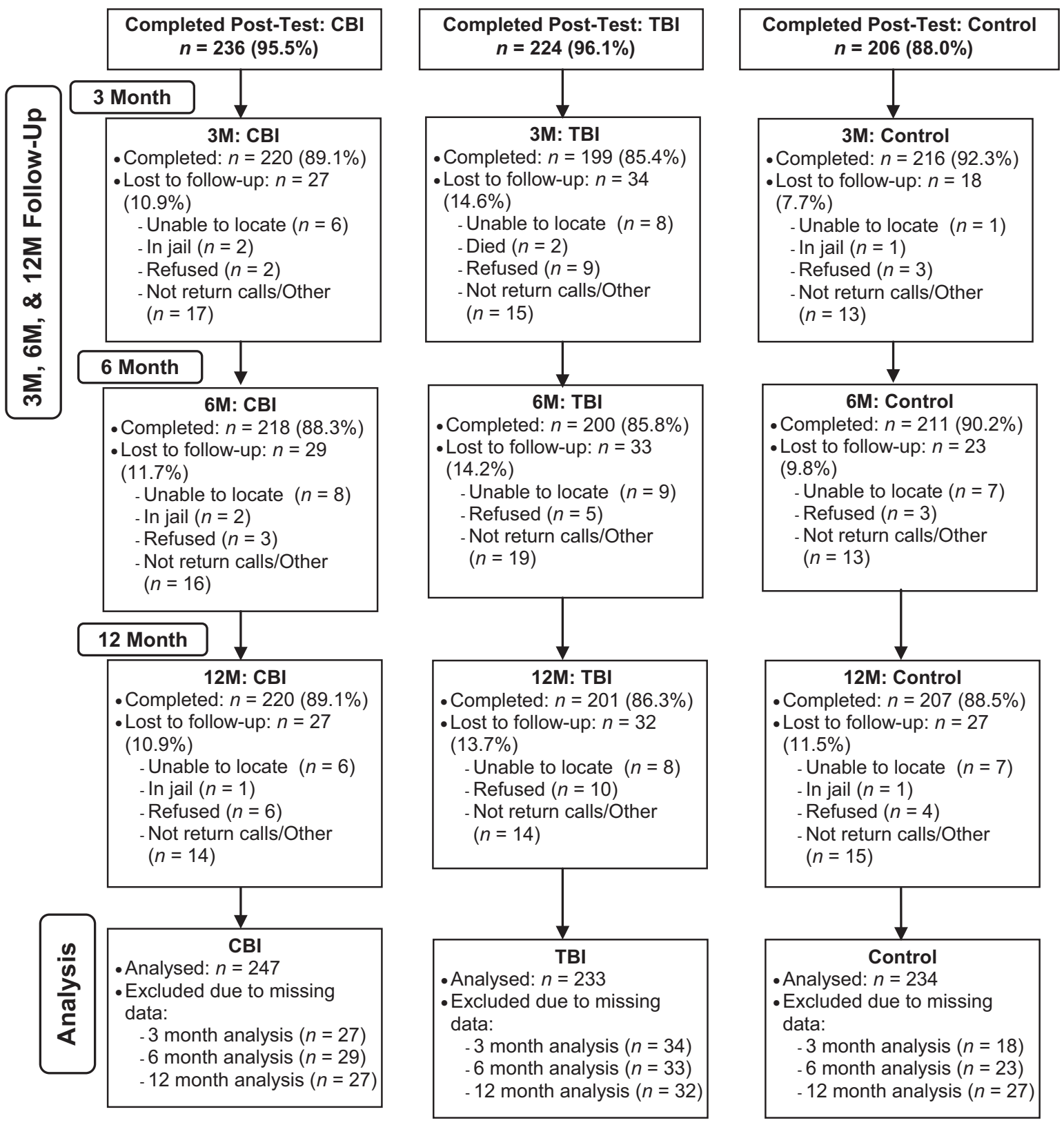

Figure I Continued

significant. Regarding demographics in general, cannabis use, other drug use and delinquency was related positively to male gender, high school grade level or dropping out, African American race and failing grades. Alcohol use was related significantly to high school grade level or dropping out. African American race was associated positively with marijuana use and delinquency, whereas other race was associated positively with other drug use and alcohol use.

\section{DISCUSSION}

To our knowledge, this study is the first to use a universal prevention approach to examine the potential efficacy of
BIs among adolescents in primary care who have yet to initiate cannabis use. Reflecting the increased use and subsequent salience of technology among adolescents, the CBI was efficacious in preventing cannabis use and reducing involvement with cannabis and other drugs, with small but clinically meaningful effect sizes $(0.12$ 0.14). Given demands placed upon medical staff, using computers for delivery of BIs could facilitate translation into routine practice at FQHCs. The TBI was efficacious in attenuating risk behaviors associated with cannabis use in the short term, namely alcohol, other drug use and delinquency, with effect sizes ranging from 0.11 to 0.36 ; however, the TBI did not prevent cannabis use. These findings are consistent with a prior paper from this study 
Table 2 Baseline demographic and substance use characteristics by condition.

\begin{tabular}{|c|c|c|c|c|}
\hline Background characteristics & $\begin{array}{l}\text { Total } \\
n=714 \\
\% / \text { mean }(S D)\end{array}$ & $\begin{array}{l}\text { TBI } \\
n=233 \\
\% / \text { mean }(S D)\end{array}$ & $\begin{array}{l}C B I \\
n=247 \\
\% / \text { mean }(S D)\end{array}$ & $\begin{array}{l}\text { Control } \\
n=234 \\
\% / \text { mean }(S D)\end{array}$ \\
\hline \multicolumn{5}{|l|}{ Demographics } \\
\hline Male & $43.0 \%$ & $45.5 \%$ & $44.5 \%$ & $38.9 \%$ \\
\hline African American race & $63.7 \%$ & $64.0 \%$ & $62.4 \%$ & $65.0 \%$ \\
\hline Hispanic ethnicity & $9.2 \%$ & $10.8 \%$ & $7.0 \%$ & $9.8 \%$ \\
\hline Age* & $14.9(1.9)$ & $15.2(1.8)$ & 14.7 (1.9) & $14.9(2.1)$ \\
\hline Grade levels $6-8^{*}$ & $36.5 \%$ & $30.1 \%$ & $40.1 \%$ & $39.3 \%$ \\
\hline Failing grades & $17.1 \%$ & $14.6 \%$ & $16.6 \%$ & $20.1 \%$ \\
\hline \multicolumn{5}{|l|}{ Drug use behaviors } \\
\hline Other illegal drug use (ever) & $6.9 \%$ & $7.7 \%$ & $7.3 \%$ & $5.6 \%$ \\
\hline Frequency & $0.2(1.0)$ & $0.2(1.0)$ & $0.2(0.8)$ & $0.2(1.1)$ \\
\hline Alcohol use (ever) & $12.0 \%$ & $12.0 \%$ & $10.5 \%$ & $13.7 \%$ \\
\hline Frequency & $0.2(0.5)$ & $0.2(0.5)$ & $0.2(0.6)$ & $0.2(0.5)$ \\
\hline Delinquency (any) & $47.5 \%$ & $51.5 \%$ & $47.4 \%$ & $43.6 \%$ \\
\hline Frequency & $1.9(4.3)$ & $1.9(3.5)$ & $2.0(4.9)$ & $1.8(4.3)$ \\
\hline
\end{tabular}

${ }^{*} P \leq 0.05 . \mathrm{CBI}=$ computer brief intervention; $\mathrm{TBI}=$ therapist brief intervention; $\mathrm{SD}=$ standard deviation. Note the following variables definitions: $(1)$ race $=$ African American versus other; (2) grade levels = 6-8th; 9th and up including dropouts; and (3) failing grades = Ds and below or dropped out.

Table 3 Within-condition (TBI, CBI) changes in perceived risk, self-efficacy and intention to use.

\begin{tabular}{lll}
\hline Variable & TBI $(n=236)$ & CBI $(n=247)$ \\
\hline $\begin{array}{lll}\text { Perceived risk } \\
\text { Baseline mean (SD) }\end{array}$ & $2.21(0.97)$ & $2.33(0.90)$ \\
Post-test mean (SD) & $2.24(0.90)$ & $2.54(0.72)$ \\
$\quad$ Difference in mean ( SD) & $0.03(0.85)$ & $0.21(0.74)$ \\
\% Change in mean & $1.4 \%$ & $9.0 \%{ }^{* * *}$ \\
Self-efficacy & & \\
Baseline mean (SD) & $3.82(1.59)$ & $3.91(1.51)$ \\
Post-test mean (SD) & $4.17(1.47)$ & $4.36(1.28)$ \\
Difference in mean & $0.43(1.32)$ & $0.49(1.32)$ \\
$\quad \%$ Change in mean & $9.2 \%{ }^{* * *}$ & $11.5 \% * * *$ \\
Intention to use & & \\
Baseline mean (SD) & $1.21(0.49)$ & $1.23(0.55)$ \\
Post-test mean (SD) & $1.20(0.55)$ & $1.23(0.55)$ \\
Difference in mean & $0.01(0.59)$ & $0.01(0.65)$ \\
\% Change in mean & $0.8 \%$ & $0.8 \%$ \\
& & \\
\hline
\end{tabular}

${ }^{* * *} P \leq 0.001 . n$ shown is for baseline; three therapist brief intervention (TBI) participants did not complete the post-test and three computer brief intervention (CBI) participants did not complete the post-test. $\mathrm{SD}=$ standard deviation.

among cannabis users, which showed greater evidence for the CBI than the TBI [25]. Conclusions regarding BI efficacy vary based on substance, problem severity, setting and delivery mechanism. For example, a universal prevention-focused, computerized, alcohol BI among college freshman showed greater effects for non-drinkers than low-risk drinkers [30]; however, other studies have found greater effects for selective or indicated prevention samples (substance users) than universal prevention samples [42]. Further, a recent review concluded that TBIs were more effective than CBIs among college students who misused alcohol [43].

Variation in BI content may also explain differences in findings across studies. Although our BIs were conceptualized to have parallel content, in practice the delivery mechanism affected the content. Therapists were given autonomy to focus the TBI based on participant interaction; thus, the therapist may have placed greater emphasis on risk behaviors other than cannabis (e.g. half the youth reported a least one act of delinquency), while the CBI focused more consistently on cannabis use. In contrast, although tailored, the CBI the content was set a priori, with greater emphasis on cannabis and the connection to other risk behaviors, which was reflected in significant increases at post-test in ratings of perceived risk. Alternatively, although both BIs aimed to increase self-efficacy and commitment talk for abstinence by presenting hypothetical risk situations, the TBI was presented in discussion format whereas the CBI included interactive videos modeling how youth could handle risk situations to avoid potential consequences (e.g. health, social, legal).

Future studies are needed to delineate the essential elements of computer and therapist BIs addressing universal substance use prevention among adolescents. For instance, decisional balance exercises are associated with poorer outcomes in one review and better outcomes in another $[43,44]$, perhaps reflecting differences in therapist skills than specific content. Identification of therapist behaviors that are associated with worse outcomes is another important area of future research, with 
Table 4 Efficacy of CBI and TBI (versus control) on any cannabis use over time.

\begin{tabular}{|c|c|c|c|c|}
\hline Outcome & $\begin{array}{l}C B I \\
\%(n)\end{array}$ & $\begin{array}{l}\text { Control } \\
\%(n)\end{array}$ & $\begin{array}{l}\text { Percentage-point } \\
\text { difference }(95 \% \mathrm{CI})\end{array}$ & $\begin{array}{l}\text { Relative rate } \\
(95 \% \mathrm{CI})\end{array}$ \\
\hline Point prevalence at 3 months & $5.00(11)^{\mathrm{a}}$ & $7.87(17)^{\mathrm{i}}$ & $-2.87(-7.47-1.73)$ & $0.64(0.30-1.32)$ \\
\hline Point prevalence at 6 months & $5.96(13)^{\mathrm{b}}$ & $9.01(19)^{\mathrm{j}}$ & $-3.05(-8.02-1.94)$ & $0.66(0.34-1.31)$ \\
\hline Point prevalence at 12 months & $10.91(24)^{\mathrm{c}}$ & $14.01(29)^{\mathrm{k}}$ & $-3.10(-9.37-3.17)$ & $0.78(0.47-1.29)$ \\
\hline Any use over 12 months & $16.82(37)^{\mathrm{d}}$ & $24.16(50)^{1}$ & $-7.34(-14.98-0.00)^{*}$ & $0.70(0.48-1.00)$ \\
\hline Outcome & $\begin{array}{l}\text { TBI } \\
\%(n)\end{array}$ & $\begin{array}{l}\text { Control } \\
\%(n)\end{array}$ & $\begin{array}{l}\text { Percentage-point } \\
\text { difference }(95 \% \mathrm{CI})\end{array}$ & $\begin{array}{l}\text { Relative rate } \\
(95 \% \mathrm{CI})\end{array}$ \\
\hline Point prevalence at 3 months & $6.53(13)^{\mathrm{e}}$ & $7.87(17)^{\mathrm{i}}$ & $-1.34(-6.31-3.63)$ & $0.83(0.42-1.66)$ \\
\hline Point prevalence at 6 months & $9.00(18)^{\mathrm{f}}$ & $9.00(19)^{\mathrm{j}}$ & $0.00(-5.54-5.54)$ & $1.00(0.54-1.85)$ \\
\hline Point prevalence at 12 months & $10.95(22)^{\mathrm{g}}$ & $14.01(29)^{\mathrm{k}}$ & $-3.06(-9.46-3.34)$ & $0.78(0.46-1.31)$ \\
\hline Any use over 12 months & $20.90(42)^{\mathrm{h}}$ & $24.16(50)^{1}$ & $-3.26(-11.36-4.84)$ & $0.87(0.60-1.24)$ \\
\hline
\end{tabular}

The relative rate is the percentage in the brief intervention (BI) group divided by control group. Use rates were calculated by participants who used cannabis among those completing follow-up. $\mathrm{CBI}=$ computer brief intervention; $\mathrm{TBI}=$ therapist brief intervention; $\mathrm{CI}=$ confidence interval. $^{\mathrm{a}} 220{ }^{\mathrm{b}}{ }^{\mathrm{b}} 218$, ${ }^{\mathrm{c}} 220,{ }^{\mathrm{d}} 220,{ }^{\mathrm{e}} 199,{ }^{\mathrm{f}} 200,{ }^{\mathrm{g}} 201,{ }^{\mathrm{h}} 201,{ }^{\mathrm{i}} 216,{ }^{\mathrm{i}} 211,{ }^{\mathrm{k}} 207$ and ${ }^{\mathrm{l}} 207 .{ }^{*} P<0.05$.

Table 5 Regression analyses: efficacy of TBI and CBI (versus control) on extent of substance use and delinquency over time.

\begin{tabular}{|c|c|c|c|}
\hline Variable & $\begin{array}{l}3 M^{\mathrm{a}} \\
\operatorname{IRR}(95 \% C I)\end{array}$ & $\begin{array}{l}6 M^{\mathrm{b}} \\
\operatorname{IRR}(95 \% C I)\end{array}$ & $\begin{array}{l}12 M^{\mathrm{c}} \\
\operatorname{IRR}(95 \% C I)\end{array}$ \\
\hline \multicolumn{4}{|l|}{ Cannabis use frequency } \\
\hline Computer & $0.55(0.30,0.99)^{*}$ & $0.56(0.34,0.91)^{*}$ & $0.89(0.60,1.31)$ \\
\hline Therapist & $0.92(0.55,1.54)$ & $0.65(0.41,1.04)$ & $0.90(0.61,1.33)$ \\
\hline \multicolumn{4}{|l|}{ Other drug use frequency } \\
\hline Baseline other drug use & $1.20(1.09,1.32)^{* * *}$ & $1.20(1.09,1.32)^{* * *}$ & $1.42(1.31,1.53)^{* *}$ \\
\hline Computer & $0.48(0.29,0.79)^{* *}$ & $0.94(0.60,1.48)$ & $0.75(0.38,1.49)$ \\
\hline Therapist & $0.52(0.31,0.87)^{*}$ & $0.61(0.36,1.04)$ & $0.86(0.39,1.92)$ \\
\hline \multicolumn{4}{|l|}{ Alcohol use severity } \\
\hline Baseline alcohol use & $3.00(2.15,4.19)^{* * *}$ & $2.27(1.73,2.99)^{* * *}$ & $2.32(1.73,3.11)^{* * *}$ \\
\hline Computer & $0.86(0.48,1.55)$ & $0.63(0.39,1.01)$ & $0.82(0.50,1.34)$ \\
\hline Therapist & $1.23(0.70,2.18)$ & $0.52(0.32,0.85)^{* *}$ & $0.69(0.42,1.34)$ \\
\hline \multicolumn{4}{|l|}{ Delinquency frequency } \\
\hline Baseline delinquency & $1.25(1.17,1.32)^{* * *}$ & $1.23(1.14,1.33)^{* * *}$ & $1.19(1.12,1.26)^{* * *}$ \\
\hline Computer & $0.91(0.63,1.33)$ & $1.15(0.72,1.84)$ & $0.88(0.55,1.41)$ \\
\hline Therapist & $0.54(0.36,0.80)^{* *}$ & $0.92(0.58,1.48)$ & $0.98(0.61,1.57)$ \\
\hline
\end{tabular}

$3 \mathrm{M}=3$-month follow-up; $6 \mathrm{M}=6$-month follow-up; $12 \mathrm{M}=12$-month follow-up; $\mathrm{TBI}=$ therapist brief intervention; $\mathrm{CBI}=$ computer brief intervention; IRR = incident rate ratio; $\mathrm{CI}=$ confidence interval. IRR values $>1.0$ indicate variables associated positively with the outcome variable and values $<1.0$ indicate variables associated negatively with the outcome variable. Effect sizes: (1) cannabis use: $\mathrm{CBI}=0.12(3 \mathrm{M})$ and $0.14(6 \mathrm{M}) ;(2)$ other drug use: $\mathrm{CBI}=0.09(3 \mathrm{M})$; (3) alcohol use: TBI $=0.14(3 \mathrm{M})$; and (4) delinquency: $\mathrm{TBI}=0.36(3 \mathrm{M}) .{ }^{\mathrm{a}} n=635,{ }^{\mathrm{b}} n=629,{ }^{\mathrm{c}} n=628 .{ }^{*} P<0.05 ;{ }^{* *} P<0.01$; *** $P<0.001$

review studies suggesting that simple reflections and directiveness are counterproductive [44,45] among substance-using samples. In our study, it is unknown whether such behaviors occurred in the TBI, whereas the CBI was programmed so that it did not include such behaviors.

Although findings for this study showed short-term benefits of BIs, consistent with conclusions from reviews regarding the efficacy of motivational interviewing based BIs [46], effects were generally not sustained. Given that the American Medical Association (AMA) recommends that adolescents be asked at least annually about substance use [47], additional boosters could be delivered during subsequent visits. In order to optimize effects, a multi-modal approach could be utilized in which the computer program could be initially provided for universal prevention, followed by therapist BIs to further explore changes in risk behaviors over time.

\section{Limitations}

Several study limitations require attention. Self-report data were collected, which may be prone to response bias. 
Table 6 Regression analyses: efficacy of TBI and CBI (versus control) on extent of substance use and delinquency over time: controlling for baseline characteristics.

\begin{tabular}{|c|c|c|c|}
\hline Variable & $\begin{array}{l}3 M^{\mathrm{a}} \\
\operatorname{IRR}(95 \% C I)\end{array}$ & $\begin{array}{l}6 M^{\mathrm{b}} \\
\operatorname{IRR}(95 \% C I)\end{array}$ & $\begin{array}{l}12 M^{c} \\
\operatorname{IRR}(95 \% C I)\end{array}$ \\
\hline \multicolumn{4}{|l|}{ Cannabis use frequency } \\
\hline Computer & $0.53(0.29,0.95)^{*}$ & $0.61(0.37,0.99)^{*}$ & $0.86(0.58,1.27)$ \\
\hline Therapist & $0.84(0.49,1.42)$ & $0.66(0.41,1.06)$ & $0.94(0.21,4.18)$ \\
\hline Gender & $1.60(1.00,2.56)$ & $1.63(1.08,2.46)$ & $1.07(0.77,1.50)$ \\
\hline Education & $0.86(0.53,1.40)$ & $0.41(0.25,0.67)$ & $0.58(0.40,0.85)$ \\
\hline Race group & $2.61(1.04,6.56)^{*}$ & $4.85(1.75,13.45)$ & $1.75(0.97,3.15)$ \\
\hline Failing grade & $0.44(0.27,0.73)^{* *}$ & $0.30(0.20,0.45)$ & $0.61(0.42,0.88)$ \\
\hline Ethnicity & $1.05(0.35,3.15)$ & $1.43(0.67,3.08)$ & $1.03(0.57,1.86)$ \\
\hline \multicolumn{4}{|l|}{ Other drug use frequency } \\
\hline Baseline other drug use & $1.26(1.14,1.39)^{* * *}$ & $1.23(1.12,1.36)^{* * *}$ & $1.32(1.20,1.46)^{* * * *}$ \\
\hline Computer & $0.52(0.31,0.86)^{*}$ & $0.97(0.61,1.55)$ & $0.78(0.38,1.58)$ \\
\hline Therapist & $0.65(0.39,1.08)$ & $0.63(0.37,1.07)$ & $0.90(0.39,2.04)$ \\
\hline Gender & $0.23(0.14,0.41)^{* * *}$ & $1.13(0.73,1.74)$ & $1.27(0.69,2.33)$ \\
\hline Education & $2.56(1.66,3.94)^{* * *}$ & $1.93(1.19-3.16)^{*}$ & $1.92(1.02,3.59)^{*}$ \\
\hline Race group & $0.32(0.19,0.54)^{* * *}$ & $0.40(0.24,0.66)^{* * *}$ & $0.86(0.30,2.48)$ \\
\hline Failing grade & $0.41(0.26,0.66)^{* * *}$ & $0.36(0.23,0.55)^{* * *}$ & $0.74(0.31,1.79)$ \\
\hline Ethnicity & $0.73(0.37,1.41)$ & $0.64(0.31,1.32)$ & $0.70(0.23,2.20)$ \\
\hline \multicolumn{4}{|l|}{ Alcohol use severity } \\
\hline Baseline alcohol use & $3.06(2.15,4.36)^{* * *}$ & $2.05(1.59,2.65)^{* * *}$ & $2.20(1.67,2.90)^{* * *}$ \\
\hline Computer & $0.93(0.52,1.68)$ & $0.66(0.42,1.04)$ & $1.22(0.75,1.99)$ \\
\hline Therapist & $1.38(0.78,2.43)$ & $0.57(0.36,0.91)^{*}$ & $1.36(0.84,2.23)$ \\
\hline Gender & $0.84(0.51,1.36)$ & $0.90(0.61,1.34)$ & $0.78(0.52,1.18)$ \\
\hline Education & $0.97(0.58,1.62)$ & $0.53(0.34,0.84)^{* *}$ & $0.46(0.28,0.76)^{* *}$ \\
\hline Race group & $0.76(0.40,1.44)$ & $0.47(0.29,0.76)^{* *}$ & $0.75(0.43,1.30)$ \\
\hline Failing grade & $0.58(0.33,1.02)$ & $0.73(0.47,1.15)$ & $0.94(0.55,1.60)$ \\
\hline Ethnicity & $1.75(0.74,4.15)$ & $1.80(0.96,3.38)$ & $1.57(0.77,3.18)$ \\
\hline \multicolumn{4}{|l|}{ Delinquency frequency } \\
\hline Baseline delinquency & $1.20(1.13,1.27)^{* * *}$ & $1.21(1.12,1.31)^{* * *}$ & $1.13(1.06,1.20)^{* * *}$ \\
\hline Computer & $0.90(0.62,1.31)$ & $0.94(0.60,1.48)$ & $0.85(0.53,1.36)$ \\
\hline Therapist & $0.53(0.36,0.79)^{* *}$ & $0.81(0.51,1.30)$ & $1.03(0.64,1.65)$ \\
\hline Gender & $1.46(1.07,2.00)^{*}$ & $1.55(1.07,2.25)^{*}$ & $1.84(1.24,2.72)^{* *}$ \\
\hline Education & $1.75(1.28,2.40)^{* *}$ & $0.92(0.62,1.37)$ & $1.49(1.01,2.21)^{*}$ \\
\hline Race group & $1.86(1.10,3.16)^{*}$ & $0.76(0.44,1.31)$ & $0.99(0.55,1.78)$ \\
\hline Failing grade & $0.83(0.56,1.22)$ & $0.74(0.46,1.19)$ & $0.60(0.36,1.00)^{*}$ \\
\hline Ethnicity & $1.19(0.67,2.09)$ & $1.34(0.66,2.71)$ & $1.05(0.48,2.30)$ \\
\hline
\end{tabular}

$3 \mathrm{M}=3$-month follow-up; $6 \mathrm{M}=6$-month follow-up; $12 \mathrm{M}=12$-month follow-up; $\mathrm{TBI}=$ therapist brief intervention; $\mathrm{CBI}=$ computer brief intervention; IRR = incident rate ratio; $\mathrm{CI}=$ confidence interval. IRR values $>1.0$ indicate variables associated positively with the outcome variable and values $<1.0$ indicate variables associated negatively with the outcome variable. ${ }^{*} P<0.05 ;{ }^{* *} P<0.01 ;{ }^{* * *} P<0.001 ;{ }^{\mathrm{a}} n=635,{ }^{\mathrm{b}} n=629,{ }^{\mathrm{c}} n=628$.

To increase the accuracy of self-report, we included a urine drug screen (with excellent concordance), participants' self-administered data on computers, and follow-up staff were 'blinded' to condition assignment $[48,49]$. Although regular supervision was provided and a computer was used to prompt section content for therapists, a challenge inherent to the delivery of TBIs is fidelity. Although follow-up rates were excellent (>85\%), substance use among those not completing follow-ups was unknown; thus, analyses were limited to those completing follow-ups. Also, higher rates of attrition in the TBI at 3 months could have affected findings. Replication is required to determine generalizability to other samples (e.g. Hispanics) and settings.

\section{CONCLUSIONS}

From a public health standpoint, findings from this universal prevention study suggest that a computer BI may be particularly promising in deterring the use of cannabis and other drugs in the short term. Findings for a therapist BI were mixed, with no effects on cannabis use but shortterm effects on other risk behaviors. Future studies are needed to identify critical components of BIs, including the optimal combination of therapist and computer BIs and timing of delivery of boosters at subsequent visits.

\section{Clinical Trial registration}

ClinicalTrials.gov Identifier NCT01329315. 


\section{Declaration of interests}

None.

\section{Acknowledgements}

This project was funded by a grant (no. DA020075) from the National Institute on Drug Abuse (NIDA). We would like to thank project staff as well as the patients and medical staff at Hamilton Community Health Centers and Health Delivery Inc., and Mott Children's Health Center for their support of this project.

\section{References}

1. Johnston L. D., O'Malley P. M., Bachman J. G., Schulenberg J. E. Monitoring the Future National Survey Results on Drug Use, 1975-2011. Volume I: Secondary School Students. Ann Arbor: Institute for Social Research, The University of Michigan; 2012.

2. Brook D. W., Brook J. S., Zhang C., Cohen P., Whiteman M. Drug use and the risk of major depressive disorder, alcohol dependence, and substance use disorders. Arch Gen Psychiatry 2002; 59: 1039-44.

3. Lynskey M. T., Heath A. C., Bucholz K. K., Slutske W. S., Madden P. A., Nelson E. C. et al. Escalation of drug use in early-onset cannabis users vs co-twin controls. JAMA 2003; 289: 427-33.

4. McCabe S. E., West B. T., Cranford J. A., Ross-Durow P., Young A., Teter C. J. et al. Medical misuse of controlled medications among adolescents. Arch Pediatr Adolesc Med 2011; 165: 729-35.

5. Tobler N. S., Stratton H. H. Effectiveness of school-based drug prevention programs: a meta-analysis of the research. J Prim Prev 1997; 18: 71-128.

6. D’Amico E. J., Tucker J. S., Miles J. N. V., Zhou A. J., Shih R. A., Green J. H. D. Preventing alcohol use with a voluntary after-school program for middle school students: results from a cluster randomized controlled trial of CHOICE. Prev Sci 2012; 13: 415-25.

7. Hecht M. L., Marsiglia F. F., Elek E., Wagstaff D. A., Kulis S., Dustman P. et al. Culturally grounded substance use prevention: an evaluation of the keepin' it R.E.A.L. curriculum. Prev Sci 2003; 4: 233-48.

8. Catalano R. F., Berglund M. L., Ryan J. A. M., Lonczak H. S., Hawkins J. D. Positive youth development in the United States: research findings on evaluations of positive youth development programs. Prev Treat 2002; 5: 1-111.

9. Hanley S., Ringwalt C., Ennett S. T., Vincus A. A., Bowling J. M., Haws S. W. et al. The prevalence of evidence-based substance use prevention curricula in the nation's elementary schools. J Drug Educ 2010; 40: 51-60.

10. Conrod P. J., Castellanos-Ryan N., Strang J. Brief, personality-targeted coping skills interventions and survival as a non-drug user over a 2-year period during adolescence. Arch Gen Psychiatry 2010; 67: 85-93.

11. Sussman S., Sun P., Rohrbach L. A., Spruijt-Metz D. Oneyear outcomes of a drug abuse prevention program for older teens and emerging adults: evaluating a motivational interviewing booster component. Health Psychol 2012; 31:47685.

12. Faggiano F., Vigna-Taglianti F., Burkhart G., Bohrn K., Cuomo L., Gregori D. et al. The effectiveness of a school- based substance abuse prevention program: 18-month follow-up of the EU-Dap cluster randomized controlled trial. Drug Alcohol Depend 2010; 108: 56-64.

13. Shamblen S. R., Derzon J. H. A preliminary study of the population-adjusted effectiveness of substance abuse prevention programming: towards making IOM program types comparable. J Prim Prev 2009; 30: 89-107.

14. Monti P. M., Barnett N. P., Colby S. M., O'Leary T. A. Motivational enhancement of alcohol-involved adolescents. In: Monti P. M., Colby S. M., O'Leary T. A., editors. Adolescents, Alcohol and Substance Abuse: Reaching Teens through Brief Interventions, New York: Guilford Press; 2001, pp. 145-82.

15. Miller W. R., Rollnick S. Motivational Interviewing, 3rd edn. Helping People for Change (Applications of Motivational Interviewing). New York: Guilford Press; 2012.

16. Jensen C. D., Cushing C. C., Aylward B. S., Craig J. T., Sorell D. M., Steele R. G. Effectiveness of motivational interviewing interventions for adolescent substance use behavior change: a meta-analytic review. J Consult Clin Psychol 2011; 79: 433-40.

17. Bertholet N., Daeppen J. B., Weitlisbach V., Fleming M., Burnand B. Reduction of alcohol consumption by brief intervention in primary care. Arch Intern Med 2005; 165: 986-95.

18. Mason M., Pate P., Drapkin M., Sozinho K. Motivational interviewing integrated with social network counseling for female adolescents: a randomized pilot study in urban primary care. J Subst Abuse Treat 2011; 41: 148-55.

19. Millstein S. G., Marcell A. V. Screening and counseling for adolescent alcohol use among primary care physicians in the United States. Pediatrics 2003; 111: 114-25.

20. Ozer E. J., Tschann J. M., Pasch L. A., Flores E. Violence perpetration across peer and partner relationships: co-occurrence and longitudinal patterns among adolescents. J Adolesc Health 2004; 34: 64-71.

21. Harris S. K., Csémy L., Sherritt L., Starostova O., Van Hook S., Johnson J. et al. Computer-facilitated substance use screening and brief advice for teens in primary care: an international trial. Pediatrics 2012; 129: 1-12.

22. Haller D., Meynard A., Lefebvre D., Tylee A., Narring F., Broers B. Brief intervention addressing excessive cannabis use in young people consulting their GP: a pilot study. $\mathrm{Br} \mathrm{J}$ Gen Pract 2009; 59: 166-72.

23. Knight J. R., Sherritt L., Van Hook S., Gates E. C., Levy S., Chang G. Motivational interviewing for adolescent substance use: a pilot study. J Adolesc Health 2005; 37: 167-9.

24. D'Amico E. J., Miles J. N., Stern S. A., Meredith L. S. Brief motivational interviewing for teens at risk of substance use consequences: a randomized pilot study in a primary care clinic. J Subst Abuse Treat 2008; 35: 53-61.

25. Walton M. A., Bohnert K., Resko S., Barry K. T., Chermack S. T., Zucker R. A. et al. Computer and therapist based brief interventions among cannabis-using adolescents presenting to primary care: one year outcomes. Drug Alcohol Depend 2013; 132: 646-53.

26. McCambridge J., Strang J. Development of a structured generic drug intervention model for public health purposes: a brief application of motivational interviewing with young people. Drug Alcohol Rev 2003; 22: 391-9.

27. McCambridge J., Strang J. The efficacy of single-session motivational interviewing in reducing drug consumption and perceptions of drug-related risk and harm among young people: results from a multi-site cluster randomized trial. Addiction 2004; 99: 39-52. 
28. McCambridge J., Strang J. Deterioration over time in effect of motivational interviewing in reducing drug consumption and related risk among young people. Addiction 2005; 100: $470-8$.

29. Maio R. F., Shope J. T., Blow F. C., Gregor M. A., Zakrajsek J. S., Weber J. E. et al. A randomized controlled trial of an emergency department-based interactive computer program to prevent alcohol misuse among injured adolescents. Ann Emerg Med 2005; 45: 420-9.

30. Bingham C. R., Barretto A. I., Walton M. A., Bryant C. M., Shope J. T., Raghunathan T. E. Efficacy of a web-based, tailored, alcohol prevention/intervention program for college students: 3 month follow-up. J Drug Educ 2011; 41: 40530.

31. Kypri K., Langley J. D., Saunders J. B., Cashell-Smith M. L., Herbison P. Randomized controlled trial of web-based alcohol screening and brief intervention in primary care. Arch Intern Med 2008; 168: 530-6.

32. Sieving R. E., Beuhring T., Resnick M. D., Bearinger L. H., Shew M., Ireland M. et al. Development of adolescent self-report measures from the National Longitudinal Study of Adolescent Health. J Adolesc Health 2001; 28: 73-81.

33. Harris K., Florey F., Tabor J., Bearman P., Jones J., Udry J. The National Longitudinal Study of Adolescent Health: research design. 2003. Available at: http://www.cpc.unc.edu/ projects/addhealth/design (accessed 21 May 2008). (Archived at http://www.webcitation.org/6Mcrg96q8 on 14 January 2014).

34. Johnston L. D., O’Malley P. M., Bachman P. M., Schulenberg J. E. Monitoring the Future: National Results on Adolescent Drug Use: Overview of key findings, 2003. Report no. NIH Publication no. 04-5506. Bethesda, MD: National Institute on Drug Abuse; 2004.

35. Ellickson P. L., Bell R. M. Prospects for Preventing Drug Use among Young Adolescents. Santa Monica, CA: RAND Corporation; 1990.

36. Bush K., Kivlahan D. R., McDonell M. B., Fihn S. D., Bradley K. A. The AUDIT alcohol consumption questions (AUDIT-C): an effective brief screening test for problem drinking. Ambulatory Care Quality Improvement Project (ACQUIP). Alcohol Use Disorders Identification Test. Arch Intern Med 1998; 158: 1789-95.

37. Chung T., Colby S. M., Barnett N. P., Monti P. M. Alcohol Use Disorders Identification Test: factor structure in an adolescent emergency department sample. Alcohol Clin Exp Res 2002; 26: 223-31.

38. Zimmerman M. A., Ramirez-Valles J., Zapert K. M., Maton K. I. A longitudinal study of stress-buffering effects for urban
African American male adolescent problem behaviors and mental health. J Community Psychol 2000; 28: 17-33.

39. Baer J. S., Peterson P. L. Adolescents and young adults. In: Miller W. R., Rollnick S., editors. Motivational Interviewing: Preparing People for Change, 2nd edn. New York: Guilford Press; 2002, pp. 320-32.

40. Moyers T. B. The Global Rating of Motivational Interviewing Therapists. Center on Alcoholism, Substance Use, and Addictions. 2004. Available at: http://casaa.unm.edu/ download/GROMIT.pdf (accessed 23 March 2009). (Archived at http://www.webcitation.org/6MxRYOXnn on 28 January 2014).

41. Gottfredson D. C., Wilson D. B. Characteristics of effective school-based substance abuse prevention. Prev Sci 2003; 4: 27-38.

42. McCambridge J., Hunt C., Jenkins R. J., Strang J. Cluster randomised trial of the effectiveness of motivational interviewing for universal prevention. Drug Alcohol Depend 2011; 114: 177-84.

43. Carey K. B., Scott-Sheldon L. A. J., Elliott J. C., Garey L., Carey M. P. Face-to-face versus computer-delivered alcohol interventions for college drinkers: a meta-analytic review, 1998 to 2010. Clin Psychol Rev 2012; 32: 690-703.

44. Apodaca T. R., Longabaugh R. Mechanisms of change in motivational interviewing: a review and preliminary evaluation of the evidence. Addiction 2008; 104: 70515.

45. Tollison S. J., Mastroleo N. R., Witkiewitz K., Lee C. M., Ray A. E., Larimer M. E. The relationship between baseline drinking status, peer motivational interviewing microskills, and drinking outcomes in a brief alcohol intervention for matriculation college students: a replication. Behav Ther 2013; 44: 137-51.

46. Smedslund G., Berg R. C., Hammerstrom K. T., Steiro A., Leiknes K. A., Dahl H. M. et al. Motivational interviewing for substance abuse (Review). Cochrane Database Syst Rev 2011; 11: $1-128$.

47. American Medical Association. Guidelines for Adolescent Preventive Services (GAPS). Chicago, IL: American Medical Association; 1997.

48. Brener N. D., Billy J. O., Grady W. R. Assessment of factors affecting the validity of self-reported health-risk behavior among adolescents: evidence from the scientific literature. J Adolesc Health 2003; 33: 436-57.

49. Dennis M., Titus J. C., Diamond G., Donaldson J., Godley S. H., Tims F. M. et al. The Cannabis Youth Treatment (CYT) experiment: rationale, study design and analysis plans. Addiction 2002; 97: 16-34. 